CLINICAL STUDY

\title{
Association of proinsulin and hepatic steatosis in a random, population-based sample
}

\author{
Sonja Wengert ${ }^{1, *}$, Suemeyra Oeztuerk ${ }^{1,{ }^{*}}$, Mark Martin Haenle ${ }^{1}$, Wolfgang Koenig ${ }^{2}$, Armin Imhof ${ }^{2}$, \\ Bernhard Otto Boehm ${ }^{1}$, Manfred Wilhelm ${ }^{3}$, Ren Mao ${ }^{4}$, Richard Andrew Mason ${ }^{5}$, Wolfgang Kratzer ${ }^{1}$ and \\ the EMIL Study group \\ Departments of ${ }^{1}$ Internal Medicine I and ${ }^{2}$ Internal Medicine II, University Hospital Ulm, Albert-Einstein-Allee 23, D-89081 Ulm, Germany. ${ }^{3}$ Department \\ of Mathematics, Natural Sciences and Economic Studies (Biostatistics), University of Applied Sciences Ulm, Albert-Einstein-Allee 55, D-89081 Ulm, \\ Germany, ${ }^{4}$ Department of Gastroenterology, The First Affiliated Hospital of Sun Yat-sen University, 58 Zhongshan II Road, 510080 Guangzhou, People's \\ Republic of China and ${ }^{5}$ Louis Stokes Cleveland Department of Veterans Affairs Medical Center, 10701 East Boulevard, Cleveland, Ohio 44106, USA \\ (Correspondence should be addressed to W Kratzer; Email: wolfgang.kratzer@uniklinik-ulm.de)
}

*(S Wengert and S Oeztuerk contributed equally to this work)

\begin{abstract}
Objective: Proinsulin may represent a predictive marker for assessing insulin resistance and reduced $\beta$-cell function. The objective of this study was to investigate the association between hepatic steatosis, proinsulin and other parameters in a random, population-based sample.

Design: Cross-sectional study, conducted in south-western Germany.

Methods: Upper abdominal ultrasound examinations were performed in 343 subjects (147 females, 196 males; average age $40.0 \pm 11.5$ years). Proinsulin, the proinsulin-to-insulin ratio and other laboratory parameters were determined, and the BMI, waist-to-hip ratio (WHR) and other anthropometric data were documented.

Results: Hepatic steatosis was observed in 80 subjects (23.3\%: 29.6\%, males; $15.0 \%$, females). Multivariate analysis showed an association with hepatic steatosis for male gender $(P=0.0212)$, advancing age $(P=0.0241)$, elevated BMI $(P<0.0001)$, elevated WHR $(P=0.0024)$, alanine aminotransferase $(P=0.0046)$, proinsulin $(P=0.0403)$ and proinsulin-to-insulin ratio $(P=0.0116)$.

Conclusions: There is an association between elevated proinsulin concentrations and hepatic steatosis.
\end{abstract}

European Journal of Endocrinology 168 195-202

\section{Introduction}

Obesity is one of the fastest growing health problems worldwide $(1,2)$. In Europe, the prevalence of obesity has tripled since 1980 (3). Obesity is closely associated with non-alcoholic fatty liver disease (NAFLD), which is the most common chronic liver disease, affecting nearly $30 \%$ of the population in Western industrial nations $(4,5,6,7,8,9,10)$. NAFLD as a clinical entity can be further subdivided histologically into a form characterised by simple hepatic steatosis and another in which the steatosis is complicated by non-specific inflammation; both, however, constitute benign forms of the disorder. In its more malignant form, the disorder presents as non-alcoholic steatohepatitis (NASH). Histologically, these patients exhibit both inflammation and liver damage with the potential for progression toward fibrosis, cirrhosis or hepatocellular carcinoma $(11,12)$. There is an association between hepatic steatosis and the development of insulin resistance and type 2 diabetes mellitus $(13,14)$. In fact, patients with NAFLD have a threefold increased risk of developing type 2 diabetes mellitus (15). In addition, the disorder is associated with other components of the metabolic syndrome $(4,12,16,17,18,19)$.

Pfutzner et al. (20) measured intact proinsulin as a means of assessing for insulin resistance. As insulin resistance worsens, proinsulin secretion increases secondary to the pancreas' reduced capacity to convert this prohormone precursor to insulin. Thus, elevated proinsulin concentrations may provide evidence of abnormal $\beta$-cell function and, hence, serve as a predictor for the development of diabetes $(20,21,22)$. Proinsulin has also been shown to be a reliable marker for rapidly progressing type 2 diabetes mellitus (22). In addition, proinsulin inhibits fibrinolysis and together with insulin resistance contributes to the risk of cardiovascular disease $(23,24)$. Objective of this study was to investigate the association between hepatic steatosis, proinsulin and other parameters in a random population-based sample. 


\section{Materials and methods}

\section{Study population}

The Echinococcus Multilocularis and Internal Diseases in Leutkirch (EMIL) Study is a population-based crosssectional study conducted from November to December 2002 in Leutkirch, a town in south-western Germany. Of 4000 randomly selected inhabitants, a total of 2445 subjects aged 10-65 years were included in the study (participation rate, 62.8\%) (25). Following application of the exclusion criteria, 343 subjects were included in the present analysis. Exclusion criteria were: subjects $<18$ years; seropositivity for hepatitis B or C; history of haemochromatosis; subjects fasting $<8 \mathrm{~h}$ at the time of ultrasound examination; and elevated alcohol consumption (women: $>20 \mathrm{~g} /$ day; men: $>40 \mathrm{~g} /$ day). Also excluded were subjects with incomplete laboratory results (Fig. 1). Two of the 343 subjects reported type 2 diabetes mellitus.

The study was conducted in conformity with the principles of the Helsinki Declaration and Good Clinical Practice recommendations and was approved by the Ethics Commission of the State Medical Council of Baden-Württemberg. All study participants provided their informed written consent.

\section{Examination methods}

Patient history, including demographics, leisure activities, past medical history, family medical history, medication history as well as nicotine and alcohol use and nutritional habits were documented using a standardised interview.

\section{Anthropometric data}

Body height, body weight, and hip and waist circumference were measured. The BMI and the waist-to-hip

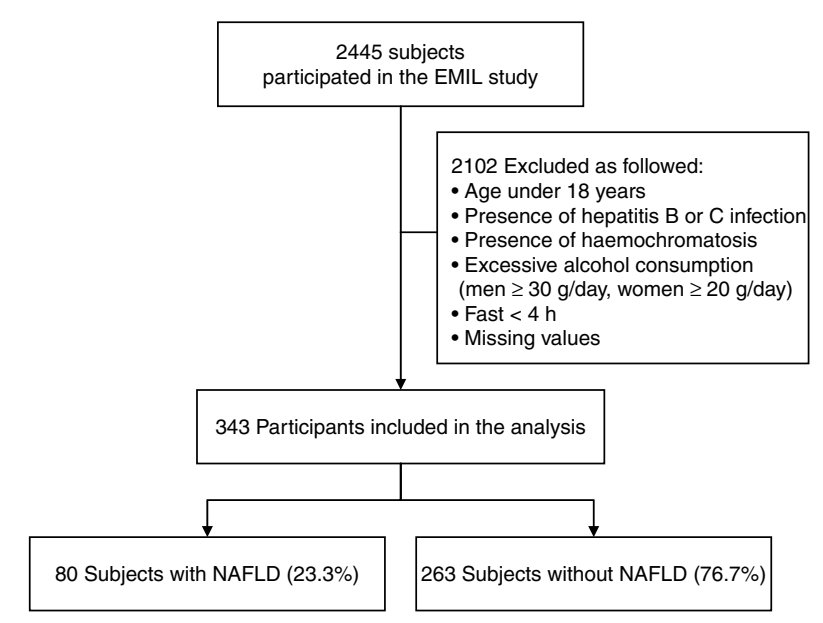

Figure 1 Flow of the subjects across the study. ratio (WHR) were calculated according to the recommendations of the World Health Organization (26).

\section{Laboratory testing}

About $25 \mathrm{ml}$ whole blood was obtained from each study participant through phlebotomy of the cubital vein. Subjects' insulin concentration was determined using a RIA (Immunotech, Beckman Coulter Company, Brea, USA; Insulin (e) IRMA kit, Canada); for proinsulin, a immunoenzymometric assay (ZenTech s.a. 4031, Angleur, Belgium) was used. For this assay, the intra-assay $\mathrm{CV}$ was $4.3 \%$ for $6.97 \mathrm{pmol} / \mathrm{l}$ and $7.4 \%$ for $60.3 \mathrm{pmol} / \mathrm{l}$; the interassay CV was $6.8 \%$ for $7.32 \mathrm{pmol} / \mathrm{l}$ and $5.5 \%$ for $64.7 \mathrm{pmol} / \mathrm{l}$. In testing for proinsulin, no cross-reactions with insulin or C-peptide were observed. Random glucose, alanine aminotransferase (ALT), aspartate aminotransferase (AST), $\gamma$-glutamyl transferase (GGT), alkaline phosphatase (AP), C-reactive protein (CRP), albumin, cholesterol, HDL, transferring and ferritin were measured using the Dimension XL unit (Dade Behring, Inc., Newark, DE 19714, USA). Fibrinogen and coeruloplasmin were measured using the Siemens Dade Behring BII Nephelometer (Siemens Healthcare Diagnostics $\mathrm{GmbH}$; Ludwig-Erhard-Straße 12; 65760 Eschborn, Germany). The concentration of LDL was calculated using the Friedewald formula: LDL-cholesterol $=$ total cholesterol $-\mathrm{HDL}-($ triglycerides $\times 0.45)(27)$.

The Institute of Clinical Chemistry of the University Hospital of Ulm defines the normal reference range for the concentration of proinsulin to be $<9.4 \mathrm{pmol} / \mathrm{l}$ (28). Participants' pre-examination fasting periods were documented historically. Participants with reported fasting times $<8 \mathrm{~h}$ were excluded from the study. Regular precision controls were performed to assure proper functioning of all laboratory equipment.

\section{Ultrasound examination and criteria for hepatic steatosis}

Ultrasound examinations were performed under standardised conditions by specially trained examiners using four identical HDI 5000 diagnostic ultrasound units (ATL Ultrasound, Philips Medical Systems, Bothell, WA, USA). Unclear or pathological findings were reviewed by an experienced supervisor ( $>4000$ ultrasonographic examinations per year). As far as possible, identical settings were maintained for all units. Findings were documented using a standardised recording questionnaire. Examinations included assessment of the liver, gallbladder, kidneys and spleen. The liver was assessed with respect to size, the presence of focal lesions and evidence of hepatic steatosis. The diagnosis of hepatic steatosis was made on the basis of criteria established by Saverymuttu et al. (29), Hamaguchi et al. (30) and Charatcharoenwitthaya \& Lindor (31). The hepatic parenchyma was compared with the renal 
parenchyma under consideration of the dorsal echo attenuation, visualisation of the diaphragm and ability to assess the intrahepatic vessels. The degree of steatosis was assigned to classes of 'none' (grade 0), 'mild' (grade I), 'moderate' (grade II) and 'severe' (grade III).

\section{Statistical analysis}

Statistical calculations were performed using the SAS 9.2 statistics software package (SAS Institute, Inc., Cary, NC, USA). Data were first analysed descriptively. Mean and s.D. were determined for continuous variables. Categorical data were presented with absolute and relative frequencies. In order to detect differences between subjects with and without hepatic steatosis, the Wilcoxon rank-sum test was used for continuous variables, while, for categorical variables, the $\chi^{2}$ test or, when the number of cases was too small, Fisher's exact test were used.

In a further analysis, proinsulin values were divided into three groups of equal size (tertiles) for subjects with and without hepatic steatosis. The ranges of the three respective tertiles for subjects without hepatic steatosis were as follows: first tertile: $3.26-9.11 \mathrm{pmol} / \mathrm{l}$; second tertile: $9.13-10.8 \mathrm{pmol} / \mathrm{l}$; third tertile: $10.9-47.1 \mathrm{pmol} / \mathrm{l}$ respectively. For subjects with hepatic steatosis, the ranges of the three respective tertiles were as follows: first tertile: $4.09-11.0 \mathrm{pmol} / \mathrm{l}$; second tertile: $11.20-14.0 \mathrm{pmol} / \mathrm{l}$; third tertile: 14.1-35.5 pmol/l. In order to demonstrate differences between the three groups, the Kruskal-Wallis test for constant variables and the $\chi^{2}$ test for categorical variables were used. Bivariate logistic regression was performed to assess the association between hepatic steatosis and proinsulin as well as other factors, including age, BMI, WHR, gender, ALT, AST and GGT, which have been reported in the literature to influence the development of hepatic steatosis. Also studied were insulin and the proinsulin-to-insulin ratio. Variables that showed an association with hepatic steatosis in the bivariate analysis $(\alpha=0.20)$ were included in the multivariate analysis. Stepwise logistic regression was used for the multivariate analyses. Statistical significance was set at $\alpha=0.10$. For bi- and multivariate analyses, laboratory parameters were standardised (z-transformed) in order to determine the effect on the adjusted odds ratio (OR) by increase of one s.D. Area under the receiver operating characteristic curve (ROC-AUC) analysis was used to evaluate the diagnostic utility of those laboratory parameters that showed an association in the multivariate analysis. The DeLong and Clarke-Pearson approach was used to compare the ROC curves of different models.

All tests were two-tailed. Statistical significance was set at $\alpha=0.05$. The $P$ value was given to four decimal places, while the OR and 95\% confidence interval (CI) were given to three decimal places.

\section{Results}

Complete clinical profiles, anthropometric and ultrasonographic data and laboratory findings were available for 343 subjects ( 147 women, $42.9 \%$; 196 men, $57.1 \%$; average age $40.0 \pm 11.5$ years). Ultrasonographic evidence of hepatic steatosis was documented in 80 subjects $(23.3 \%)$. NAFLD was more common in men $(29.6 \%, n=58)$ than in women $(15.0 \%, n=22)$. The difference in the frequency of NAFLD between men and women was statistically significant $(P=0.0044)$. Subjects with hepatic steatosis have, compared with persons without steatosis, higher proinsulin concentrations $(P<0.0001$; Table 1$)$.

Proinsulin concentrations were further studied in subjects with hepatic steatosis: proinsulin values for subjects with and without evidence of hepatic steatosis were grouped in tertiles and analysed. There was a statistically significant difference for WHR and insulin among subjects with hepatic steatosis. There was also a statistically significant difference for the parameters WHR and insulin in the group of subjects without evidence of hepatic steatosis (Table 2).

Bivariate analysis showed a difference between men and women with respect to hepatic steatosis

Table 1 Demographics and other characteristics of subjects with and without hepatic steatosis. These data are presented as the mean \pm S.D. or number of cases and percentage.

\begin{tabular}{|c|c|c|c|}
\hline & \multicolumn{2}{|c|}{ Hepatic steatosis } & \multirow[b]{2}{*}{$\begin{array}{c}P \\
\text { value }^{\mathrm{a}}\end{array}$} \\
\hline & $\begin{array}{c}\text { Not diagnosed } \\
(n=263)\end{array}$ & $\begin{array}{c}\text { Diagnosed } \\
(n=80)\end{array}$ & \\
\hline \multicolumn{4}{|l|}{ Demographics } \\
\hline \multicolumn{4}{|l|}{$\operatorname{Sex} n(\%)$} \\
\hline Female & $125(47.5)$ & $22(27.5)$ & 0.0015 \\
\hline Male & $138(52.5)$ & $58(72.5)$ & \\
\hline Age (years) & $37.1 \pm 11.1$ & $45.2 \pm 10.7$ & $<0.0001$ \\
\hline BMI $\left(\mathrm{kg} / \mathrm{m}^{2}\right)$ & $24.0 \pm 3.6$ & $29.7 \pm 5$ & $<0.0001$ \\
\hline WHR & $0.8 \pm 0.1$ & $0.9 \pm 0.1$ & $<0.0001$ \\
\hline \multicolumn{4}{|l|}{$\begin{array}{l}\text { Laboratory } \\
\text { parameters }\end{array}$} \\
\hline Insulin $(\mu \mathrm{U} / \mathrm{ml})$ & $6.4 \pm 4.9$ & $10.3 \pm 7.9$ & $<0.0001$ \\
\hline $\begin{array}{l}\text { Proinsulin } \\
(\mathrm{pmol} / \mathrm{l})\end{array}$ & $10.6 \pm 3.8$ & $13.4 \pm 4.5$ & $<\mathbf{0 . 0 0 0 1}$ \\
\hline $\begin{array}{l}\text { Proinsulin-insulin } \\
\text { ratio }\end{array}$ & $2.2 \pm 1.3$ & $1.7 \pm 0.8$ & 0.0004 \\
\hline ALT (U/I) & $14.0 \pm 6.3$ & $20.8 \pm 9.2$ & $<0.0001$ \\
\hline AST (U/I) & $8.9 \pm 2.6$ & $10.7 \pm 3.4$ & $<0.0001$ \\
\hline GGT (U/I) & $11.4 \pm 11.7$ & $19.7 \pm 13.5$ & $<0.0001$ \\
\hline $\mathrm{AP}(\mathrm{U} / \mathrm{l})$ & $78.4 \pm 20.5$ & $87 \pm 18.8$ & $<0.0001$ \\
\hline CRP (mg/l) & $2.1 \pm 3.8$ & $3.4 \pm 4.6$ & $<0.0001$ \\
\hline Albumin (g/l) & $41.4 \pm 4.2$ & $41.6 \pm 4$ & 0.8549 \\
\hline Fibrinogen (g/l) & $3.1 \pm 0.7$ & $3.4 \pm 0.7$ & 0.0007 \\
\hline Ferritin $(\mu \mathrm{g} / \mathrm{l})$ & $101.2 \pm 131.5$ & $177.6 \pm 188$ & $<0.0001$ \\
\hline Transferrin ( $g / l)$ & $2.6+0.5$ & $2.7+0.5$ & 0.0408 \\
\hline
\end{tabular}

ALT, alanine aminotransferase; AST, aspartate aminotransferase; AP, alkaline phosphatase; CRP, C-reactive protein; GGT, $\gamma$-glutamyl transferase; WHR, waist-to-hip ratio.

a Differences in continuous data were assessed using Wilcoxon's rank-sum test; differences in categorical data were assessed using the $\chi^{2}$ test or Fisher's exact test.

Significant values are in bold type. 
Table 2 Demographics and other characteristics of subjects with and without hepatic steatosis according to proinsulin tertiles. These data are presented as the mean \pm s.D. or number of cases and percentage. Differences in continuous data were assessed using Kruskal-Wallis test; differences in categorical data were assessed using the $\chi^{2}$ test or Fisher's exact test.

\begin{tabular}{|c|c|c|c|c|c|c|}
\hline & \multicolumn{3}{|c|}{ Subjects without hepatic steatosis, mean (S.D.) } & \multicolumn{3}{|c|}{ Subjects with hepatic steatosis, mean (S.D.) } \\
\hline & $\begin{array}{l}\text { Tertile } 1 \\
(n=87)\end{array}$ & $\begin{array}{l}\text { Tertile } 2 \\
(n=88)\end{array}$ & $\begin{array}{l}\text { Tertile } 3 \\
(n=88)\end{array}$ & $\begin{array}{l}\text { Tertile } 1 \\
(n=27)\end{array}$ & $\begin{array}{l}\text { Tertile } 2 \\
(n=26)\end{array}$ & $\begin{array}{l}\text { Tertile } 3 \\
(n=27)\end{array}$ \\
\hline \multicolumn{7}{|l|}{ Demographics } \\
\hline \multicolumn{7}{|l|}{ Gender $n(\%)$} \\
\hline Female & $44(50.6)$ & $45(51.1)$ & $36(40.9)$ & 9 (33.3) & $5(19.2)$ & $8(29.6)$ \\
\hline Male & $43(49.4)$ & $43(48.9)$ & $52(59.1)$ & $18(66.7)$ & $21(80.8)$ & $19(70.4)$ \\
\hline Age (years) & $35.7(8.8)$ & $38.5(11.9)$ & $37.0(12.2)$ & $43.0(11.7)$ & $45.0(10.6)$ & $47.6(9.8)$ \\
\hline $\mathrm{BMl}\left(\mathrm{kg} / \mathrm{m}^{2}\right)$ & 23.5 (3.3) & $23.7(3.5)$ & $24.8(3.8)^{*}$ & $29.2(4.0)^{\prime}$ & $28.8(5.9)$ & $31.1(4.9)$ \\
\hline WHR & $0.8(0.1)$ & $0.8(0.1)$ & $0.8(0.1)^{\dagger}$ & $0.9(0.1)$ & $0.9(0.0)$ & $0.9(0.1)^{*}$ \\
\hline \multicolumn{7}{|l|}{ Laboratory parameters } \\
\hline $\mathrm{ALT}(\mathrm{U} / \mathrm{I})$ & $13.2(4.6)$ & $13.0(5.7)$ & $15.8(7.8)^{\dagger}$ & $21.0(11.0)$ & $20.8(8.0)$ & $20.6(8.4)$ \\
\hline AST (U/I) & $8.7(2.5)$ & $8.7(2.2)$ & $9.2(2.9)$ & $11.1(3.3)$ & $11.0(3.4)$ & $10.0(3.5)$ \\
\hline GGT (U/I) & $11.4(16.4)$ & $10.0(6.4)$ & $12.8(9.9)^{*}$ & $17.9(11.5)$ & $20.3(16.2)$ & $21.1(12.8)$ \\
\hline AP $(U / I)$ & $73.0(17.2)$ & $78.4(18.9)$ & $83.6(23.6)^{\dagger}$ & $83.1(15.2)$ & $86.7(18.6)$ & $91.4(21.7)$ \\
\hline Insulin $(\mu \mathrm{U} / \mathrm{ml})$ & $5.4(3.6)$ & $5.4(2.6)$ & $8.3(6.9)^{7}$ & $9.4(11.4)$ & $9.0(4.2)$ & $12.4(5.7)^{t}$ \\
\hline CRP (mg/l) & $1.9(3.1)$ & $2.2(5.0)$ & $2.2(3.0)$ & $2.3(2.6)$ & $3.7(5.1)$ & $4.2(5.5)$ \\
\hline Albumin ( $\mathrm{g} / \mathrm{l})$ & $41.0(3.7)$ & $41.2(3.6)$ & $42.0(5.0)$ & $41.6(4.5)$ & $42.8(3.9)$ & $40.3(3.3)$ \\
\hline Fibrinogen (g/l) & $3.1(0.6)$ & $3.1(0.6)$ & $3.2(0.8)$ & $3.2(0.7)$ & $3.6(0.8)$ & $3.4(0.5)$ \\
\hline Ferritin $(\mu \mathrm{g} / \mathrm{l})$ & $81.2(81.9)$ & $88.4(92.6)$ & $138.8(187.6)^{\star}$ & $194.4(164.2)$ & $194.3(258.2)$ & $144.8(120.9)$ \\
\hline Transferrin (g/l) & $2.7(0.6)$ & $2.4(0.5)$ & $2.6(0.5)^{\star}$ & $2.6(0.4)$ & $2.7(0.4)$ & $2.7(0.5)$ \\
\hline $\mathrm{LDL}(\mathrm{mmol} / \mathrm{l})$ & $3.2(0.9)$ & $3.3(0.9)$ & $3.4(1.1)$ & $3.8(1.0)$ & $3.8(1.0)$ & $3.7(0.8)$ \\
\hline $\mathrm{HDL}(\mathrm{mmol} / \mathrm{l})$ & $1.6(0.4)$ & $1.6(0.3)$ & $1.5(0.4)$ & $1.4(0.4)$ & $1.3(0.3)$ & $1.2(0.2)$ \\
\hline Triglyceride $(\mathrm{mmol} / \mathrm{l})$ & $1.0(0.6)$ & $0.9(0.4)$ & $1.2(0.9)^{\dagger}$ & $1.7(1.1)$ & $2.2(1.4)$ & $2.1(1.4)$ \\
\hline \multicolumn{7}{|l|}{ Sonographic findings } \\
\hline \multicolumn{7}{|l|}{ Hepatic steatosis $n(\%)$} \\
\hline No & $87(100)$ & $88(100)$ & $88(100)$ & - & - & - \\
\hline Grade I & - & - & - & $15(55.6)$ & $12(46.2)$ & $12(44.4)$ \\
\hline Grade II/III & - & - & - & $12(44.4)$ & $14(53.9)$ & $15(55.6)$ \\
\hline \multicolumn{7}{|l|}{ Drinking habits } \\
\hline \multicolumn{7}{|c|}{ Alcohol consumption $n(\%)$} \\
\hline Former consumers & $2(2.3)$ & $2(2.3)$ & $5(5.7)$ & $1(3.7)$ & $0(0)$ & $2(7.4)$ \\
\hline $0 \mathrm{~g}$ & $34(39.1)$ & $36(40.9)$ & 35 (39.8) & 7 (25.9) & 11 (42.3) & $13(48.2)$ \\
\hline $1-20 \mathrm{~g} /$ day & $30(34.5)$ & $27(30.7)$ & $28(31.8)$ & $10(37.0)$ & $12(46.2)$ & $10(37.0)$ \\
\hline $21-40 \mathrm{~g} /$ day & $15(17.2)$ & $14(15.9)$ & $14(15.9)$ & 9 (33.3) & $3(11.5)$ & $2(7.4)$ \\
\hline$>40 \mathrm{~g} /$ day & $6(6.9)$ & $9(10.2)$ & $6(6.8)$ & - & - & - \\
\hline
\end{tabular}

ALT, alanine aminotransferase; AP, alkaline phosphatase; AST, aspartate aminotransferase; CRP, C-reactive protein; GGT, $\gamma$-glutamyl transferase; WHR, waist-to-hip ratio. ${ }^{\star} P<0.05,{ }^{\dagger} P<0.01,{ }^{\ddagger} P<0.001$.

$(P=0.0018)$. Men had a 2.4-fold increased risk for hepatic steatosis $(\mathrm{OR}=2.388 ; \mathrm{CI}=1.382-4.127)$. With respect to age, subjects aged 51-65 years had an 11.0-fold risk for hepatic steatosis $(P<0.0001)$. The risk of steatosis increased 1.2-fold for each increase by one s.D. in the proinsulin concentration. BMI and WHR also showed an association with increased proinsulin levels (Table 3).

At multivariate analysis, the parameters gender, age, BMI, WHR, ALT, proinsulin and proinsulin-toinsulin ratio showed a statistically significant association with hepatic steatosis. An increase of one s.D. in the proinsulin concentration was associated with a 1.4-fold increase in the risk of hepatic steatosis $(P=0.0403$; Table 4).

With respect to the diagnosis of hepatic steatosis, ALT shows a larger area under the ROC curve $(\mathrm{AUC}=0.7648)$ than does proinsulin $(\mathrm{AUC}=0.7503$; Table 5). The AUC of the model with all covariables $(\mathrm{AUC}=0.9101)$ identified at model selection is significantly larger than the AUC of the model without proinsulin and ALT (AUC $=0.8971)$. When the model with all covariables except proinsulin $(\mathrm{AUC}=0.9091)$ was compared with the model containing all covariables $(\mathrm{AUC}=0.9101)$, however, there was no statistically significant difference $(P=0.7337)$. Similarly, there was no statistically significant difference when comparing the model containing all covariables $(\mathrm{AUC}=0.9091)$ with the model containing all covariables except ALT $(\mathrm{AUC}=0.9049, P=0.4243$; Table 5).

\section{Discussion}

In this study, NAFLD was associated with proinsulin concentrations: subjects with higher proinsulin concentrations had an increased risk of developing hepatic steatosis. To our knowledge, this is the first populationbased study investigating the association between hepatic steatosis and proinsulin. To date, research has mainly sought to elucidate the association between 
Table 3 Relationship between variables and hepatic steatosis. Potential predictors for hepatic steatosis were evaluated by bivariate logistic regression analysis.

\begin{tabular}{|c|c|c|c|c|}
\hline & \multicolumn{2}{|c|}{ Hepatic steatosis $(n)$} & \multirow[b]{2}{*}{ OR $(95 \% \mathrm{Cl})$} & \multirow[b]{2}{*}{$P$ value } \\
\hline & No & Yes & & \\
\hline \multicolumn{5}{|l|}{ Sex } \\
\hline Female & 125 & 22 & Ref. & \\
\hline Male & 138 & 58 & $2.388(1.382-4.127)$ & 0.0018 \\
\hline \multicolumn{5}{|l|}{ Age (years) } \\
\hline $18-30$ & 70 & 5 & Ref. & \\
\hline $31-40$ & 105 & 24 & $3.200(1.166-8.785)$ & 0.0240 \\
\hline $41-50$ & 51 & 22 & $6.039(2.143-17.016)$ & 0.0007 \\
\hline $51-65$ & 37 & 29 & $10.973(3.920-30.714)$ & $<0.0001$ \\
\hline \multicolumn{5}{|l|}{$\mathrm{BMI}$} \\
\hline$<25$ & 175 & 8 & Ref. & \\
\hline $25-29$ & 71 & 42 & $12.937(5.786-28.928)$ & $<0.0001$ \\
\hline$\geq 30$ & 17 & 30 & $38.593(15.300-91.349)$ & $<0.0001$ \\
\hline \multicolumn{5}{|l|}{ WHR } \\
\hline Normal & 195 & 20 & Ref. & \\
\hline Elevated & 68 & 60 & $8.603(4.834-15.311)$ & $<0.0001$ \\
\hline Proinsulin & & & $2.064(1.506-2.829)$ & $<0.0001$ \\
\hline Insulin & & & $2.029(1.473-2.797)$ & $<0.0001$ \\
\hline $\begin{array}{l}\text { Proinsulin/ } \\
\text { insulin }\end{array}$ & & & $0.545(0.384-0.772)$ & 0.0006 \\
\hline \multicolumn{5}{|l|}{ ratio } \\
\hline ALT & & & $2.386(1.785-3.190)$ & $<0.0001$ \\
\hline AST & & & $1.806(1.407-2.319)$ & $<0.0001$ \\
\hline GGT & & & $2.021(1.484-2.752)$ & $<0.0001$ \\
\hline
\end{tabular}

ALT, alanine aminotransferase; AST, aspartate aminotransferase; GGT, $\gamma$-glutamyl transferase; WHR, waist-to-hip ratio.

aivariate logistic regression.

Significant values are in bold type.

proinsulin and coronary artery disease (CAD), metabolic syndrome and type 2 diabetes mellitus (20, 21, 23, $24,32,33)$.

A comparison of subjects positive for hepatic steatosis with elevated vs normal proinsulin levels showed no significant differences with respect to age, BMI, WHR, gender, severity of steatosis or other laboratory parameters. In agreement with findings in the literature, a statistically significant association between hepatic steatosis and proinsulin as well as other factors, including male gender, advancing age, elevated BMI and WHR and ALT concentration was found $(12,34,35,36)$. It is possible that the elevated ALT concentrations observed in subjects with hepatic steatosis may be associated with the pathomechanism underlying the development of type 2 diabetes mellitus and could be used as a predictor for type 2 diabetes mellitus (37).

The proinsulin-to-insulin ratio is lower in subjects with hepatic steatosis than in those without hepatic steatosis. An elevated proinsulin-to-insulin ratio might thus protect subjects from development of hepatic steatosis $(\mathrm{OR}=0.545)$. There have been no previous reports of an association between the proinsulinto-insulin ratio and hepatic steatosis. According to Hanley et al., there are many contradictory reports regarding an association between overweight and the proinsulin-to-insulin ratio. It is possible that nondiabetic $\beta$-cells compensate for the increased insulin demand by increasing insulin secretion. Because the secretion of proinsulin does not increase, a reduced proinsulin-to-insulin ratio is the result (38).

Considering proinsulin levels without regard to the presence of hepatic steatosis, findings published by Hanley et al. (38) reveal a significant correlation between proinsulin, WHR and body fat. Bryhni et al. reported an association between increasing age and elevated proinsulin concentrations. Bryhni et al. postulate that, with advancing age, there is a decrease in the ability of the $\beta$-cells to convert proinsulin to insulin, leading to elevated proinsulin levels. Thus, proinsulin would appear to be an early marker for $\beta$-cell dysfunction $(21,39)$. The study by Strawbridge et al. (33) identified new variants of the proinsulin gene; a predisposition for type 2 diabetes mellitus may result from alleles associated with both elevation and reduction in proinsulin concentrations.

Division of subjects into three equal groups (tertiles) based on their proinsulin concentrations revealed no statistically significant differences either for subjects with hepatic steatosis or for those without evidence supporting this diagnosis. In both groups, however, WHR and insulin values showed significant differences within the proinsulin tertiles.

When the group of subjects with ultrasonographic evidence of hepatic steatosis is examined independently of proinsulin levels, subjects with this disorder exhibit higher insulin levels. Similarly, studies by Sung et al. (12) and Ardigo et al. (36) show that higher fasting insulin concentrations are associated with an increased deposit of intrahepatic fat. There are, however,

Table 4 Stepwise logistic regression analysis to assess the independent predictors of hepatic steatosis. Multiple logistic regression analysis was performed using hepatic steatosis as the dependent variable and proinsulin levels and other variables as the independent variables. For the analysis, constant parameters were z-transformed.

\begin{tabular}{lll}
\hline & OR $(95 \% \mathrm{Cl})$ & $\boldsymbol{P}^{\text {value }}{ }^{\mathrm{a}}$ \\
\hline $\begin{array}{l}\text { Gender } \\
\text { Female } \\
\text { Male }\end{array}$ & Ref. & \\
Age & $2.598(1.153-5.851)$ & $\mathbf{0 . 0 2 1 2}$ \\
$18-30$ & & \\
$31-40$ & Ref. & \\
$41-50$ & $2.260(0.646-7.905)$ & $\mathbf{0 . 2 0 1 9}$ \\
$51-65$ & $3.370(0.892-12.727)$ & $\mathbf{0 . 0 7 3 2}$ \\
BMl & $4.668(1.224-17.797)$ & $\mathbf{0 . 0 2 4 1}$ \\
$<25$ & & \\
$25-29$ & Ref. & \\
$\geq 30$ & $5.954(2.425-14.619)$ & $<\mathbf{0 . 0 0 0 1}$ \\
WHR & $12.244(4.063-36.895)$ & $<\mathbf{0 . 0 0 0 1}$ \\
Normal & & \\
Elevated & Ref. & \\
ALT & $3.292(1.525-7.109)$ & $\mathbf{0 . 0 0 2 4}$ \\
Proinsulin & $1.709(1.180-2.474)$ & $\mathbf{0 . 0 0 4 6}$ \\
Proinsulin/insulin ratio & $1.423(1.016-1.993)$ & $\mathbf{0 . 0 4 0 3}$ \\
& $0.577(0.377-0.884)$ & $\mathbf{0 . 0 1 1 6}$ \\
\hline
\end{tabular}

ALT, alanine aminotransferase; $\mathrm{Cl}$, confidence interval; Ref, references; WHR, waist-to-hip ratio.

${ }^{a}$ Multiple logistic regression.

Significant values are in bold type. 
Table 5 Area under the receiver operating characteristic (ROC) curve for detection of steatosis hepatitis.

\begin{tabular}{lccc}
\hline & AUC & $\mathbf{9 5 \%}$ Cl & $\boldsymbol{P}$ value \\
\hline Proinsulin & 0.7503 & $0.6913-0.8093$ & 0.7172 \\
ALT & 0.7648 & $0.7062-0.8234$ & \\
Main & 0.8857 & $0.8477-0.9237$ & $\mathbf{0 . 0 0 3 7}$ \\
Main + ALT + proinsulin & 0.9101 & $0.8759-0.9444$ & \\
Main + proinsulin & 0.9049 & $0.8667-0.9431$ & 0.5996 \\
Main + ALT & 0.9091 & $0.8751-0.9430$ & \\
Main + proinsulin & 0.9049 & $0.8667-0.9431$ & 0.4243 \\
Main +ALT + proinsulin & 0.9101 & $0.8759-0.9444$ & \\
Main + ALT & 0.9091 & $0.8751-0.9430$ & 0.7337 \\
Main + ALT + proinsulin & 0.9101 & $0.8759-0.9444$ & \\
Main & 0.8857 & $0.8477-0.9237$ & $\mathbf{0 . 0 0 2 6}$ \\
Main + ALT & 0.9091 & $0.8751-0.9430$ & \\
Main & 0.8857 & $0.8477-0.9237$ & $\mathbf{0 . 0 2 6 6}$ \\
Main + proinsulin & 0.9049 & $0.8667-0.9431$ & \\
\hline
\end{tabular}

Main, all covariables (BMI, age, WHR and sex) except proinsulin and ALT; $A L T$, alanine aminotransferase; AUC, area under the curve; WHR, waistto-hip ratio.

Significant values are in bold type.

also genetic variants that influence intrahepatic fat accumulation $(40,41)$. According to Speliotes et al. (40), NAFLD is genetically determined or hereditary in $26-27 \%$ of cases. Certain variants may even exert influence over glycaemic metabolic processes.

Nearly one-third of patients with NAFLD also suffer from diabetes mellitus (15). Although hepatic steatosis and insulin resistance are associated with one another, the association between hepatic steatosis and the development of type 2 diabetes mellitus remains unclear (13). It has been postulated that insulin resistance is involved in the pathogenesis of this disorder $(13,15)$. According to Pfutzner et al. (20), elevated proinsulin levels can be considered a marker for insulin resistance. Compared with the intravenous glucose tolerance test, proinsulin has a specificity of $100 \%$ but only a limited sensitivity of $49 \%$ for the diagnosis of insulin resistance (20). Because of the significant association between proinsulin and hepatic steatosis found in this study, together with the fact that proinsulin has today become an important diagnostic tool in the diagnosis of type 2 diabetes mellitus $(20,21,22,42)$, it would appear justified to consider the presence of hepatic steatosis and elevated proinsulin levels to be a marker indicating an increased risk for the development of type 2 diabetes mellitus.

A limitation of this study is the use of ultrasonography to diagnose NAFLD. Compared with histological findings, ultrasonography has a reported sensitivity of $80-95 \%$ and a specificity of $90-95 \%$ for diagnosing this disorder $(36,43)$. Ethical and logistical factors, however, precluded the use of liver biopsy in a population-based study. The frequency of hepatic steatosis in our population sample stood at $23.3 \%$, which corresponds with findings reported in comparable studies $(4,11)$; findings also showed a predilection for males at $29.6 \%$, which also corroborates the findings of other studies (6). Another possible limitation is the fasting time before obtaining blood samples for insulin and proinsulin levels: only 343 of 2445 subjects reported a fasting time of at least $8 \mathrm{~h}$ as required for inclusion in the statistical analysis. In addition, the accuracy of fasting times depends on subjects' self-report.

In conclusion, findings of this study support an association between hepatic steatosis and elevated proinsulin concentrations. Because of the known close association of hepatic steatosis with metabolic syndrome and type 2 diabetes mellitus, proinsulin may represent a simple diagnostic criterion for the identification of patients who are at risk for these conditions. Further studies will be required to fully assess the importance of proinsulin as a diagnostic parameter.

\section{Declaration of interest}

The authors declare that there is no conflict of interest that could be perceived as prejudicing the impartiality of the research reported.

\section{Funding}

The study was initiated by the government of the state of BadenWürttemberg, Germany. Financial support was provided through the Baden-Württemberg State Health Office of the District Government of Stuttgart, Germany, as well as the Regional Health Office in Ravensburg, Germany. Further support was granted by the administration of the City of Leutkirch, Germany. Sample collection supplies and part of the laboratory testing were supplied by Sarstedt AG and Co, Nürnbrecht, Germany. B O Boehm is supported by the German Research Council (GRK 1041).

\section{Author contribution statement}

S Wengert, S Oeztuerk, M M Haenle, W Koenig, A Imhof, B O Boehm and $W$ Kratzer were involved in the design and conduct of the study. S Wengert, S Oeztuerk, M M Haenle, W Koenig, A Imhof, B O Boehm, $\mathrm{M}$ Wilhelm and R Mao collected and analysed the data. S Wengert, S Oeztuerk, M M Haenle, B O Boehm, R A Mason and W Kratzer were involved in data interpretation and manuscript writing. All authors read and approved the final version.

\section{Acknowledgements}

Members of the EMIL Study group (in alphabetical order): G Adler, A Armsen, H-M Banzhaf, M Bauerdick, U Bertling, B O Boehm, B O Brandner, S O Brockmann, M Deckert, C Dingler, S Eggink, M Fuchs, W Gaus, H Goussis, A Gruenert, M M Haenle, W Hampl, CHaug, B Hay, M-LHuetter, A Imhof, P Kern, P Kimmig, A Kirch, D Klass, W Koenig, W Kratzer, M Kron, B Manfras, K Meitinger, T Mertens, R Oehme, G Pfaff, I Piechotowski, S Reuter, T Romig, A F A von Schmiesing, G Steinbach, M Tourbier, A Voegtle, T Walcher, S Wolff.

\section{References}

1 Prentice AM. Obesity - the inevitable penalty of civilisation? British Medical Bulletin 199753 229-237. (doi:10.1093/oxfordjournals. bmb.a011610)

2 McTigue KM, Harris R, Hemphill B, Lux L, Sutton S, Bunton AJ \& Lohr KN. Screening and interventions for obesity in adults: summary of the evidence for the U.S. Preventive Services Task Force. Annals of Internal Medicine 2003139 933-949. 
3 Doak CM, Wijnhoven TM, Schokker DF, Visscher TL \& Seidell JC. Age standardization in mapping adult overweight and obesity trends in the WHO European Region. Obesity Reviews 201213 174-191. (doi:10.1111/j.1467-789X.2011.00943.x)

4 Bedogni G, Miglioli L, Masutti F, Tiribelli C, Marchesini G \& Bellentani S. Prevalence of and risk factors for nonalcoholic fatty liver disease: the Dionysos nutrition and liver study. Hepatology 200542 44-52. (doi:10.1002/hep.20734)

5 Zhou YJ, Li YY, Nie YQ, Ma JX, Lu LG, Shi SL, Chen MH \& Hu PJ. Prevalence of fatty liver disease and its risk factors in the population of South China. World Journal of Gastroenterology 200713 6419-6424. (doi:10.3748/wjg.13.6419)

6 Zelber-Sagi S, Nitzan-Kaluski D, Halpern Z \& Oren R. Prevalence of primary non-alcoholic fatty liver disease in a population-based study and its association with biochemical and anthropometric measures. Liver International 200626 856-863. (doi:10.1111/ j.1478-3231.2006.01311.x)

7 Bellentani S \& Marino M. Epidemiology and natural history of nonalcoholic fatty liver disease (NAFLD). Annals of Hepatology $2009 \mathbf{8}$ (Suppl 1) S4-S8.

8 Hou XH, Zhu YX, Lu HJ, Chen HF, Li Q, Jiang S, Xiang KS \& Jia WP. Non-alcoholic fatty liver disease's prevalence and impact on alanine aminotransferase associated with metabolic syndrome in the Chinese. Journal of Gastroenterology and Hepatology 201126 722-730. (doi:10.1111/j.1440-1746.2010.06509.x)

9 Lee S, Jin Kim Y, Yong Jeon T, Hoi Kim H, Woo Oh S, Park Y \& Soo Kim S. Obesity is the only independent factor associated with ultrasound-diagnosed non-alcoholic fatty liver disease: a crosssectional case-control study. Scandinavian Journal of Gastroenterology 200641 566-572. (doi:10.1080/00365520500319591)

10 Volzke H, Robinson DM, Kleine V, Deutscher R, Hoffmann W, Ludemann J, Schminke U, Kessler C \& John U. Hepatic steatosis is associated with an increased risk of carotid atherosclerosis. World Journal of Gastroenterology 200511 1848-1853.

11 Neuschwander-Tetri BA \& Caldwell SH. Nonalcoholic steatohepatitis: summary of an AASLD Single Topic Conference. Hepatology 200337 1202-1219. (doi:10.1053/jhep.2003.50193)

12 Sung KC, Ryan MC, Kim BS, Cho YK, Kim BI \& Reaven GM. Relationships between estimates of adiposity, insulin resistance, and nonalcoholic fatty liver disease in a large group of nondiabetic Korean adults. Diabetes Care 200730 2113-2118. (doi:10.2337/ dc07-0512)

13 Sung KC \& Kim SH. Interrelationship between fatty liver and insulin resistance in the development of type 2 diabetes. Journal of Clinical Endocrinology and Metabolism 201196 1093-1097. (doi:10.1210/jc.2010-2190)

14 Kim CH, Park JY, Lee KU, Kim JH \& Kim HK. Fatty liver is an independent risk factor for the development of type 2 diabetes in Korean adults. Diabetic Medicine 200825 476-481. (doi:10. 1111/j.1464-5491.2008.02410.x)

15 Adams LA, Waters OR, Knuiman MW, Elliott RR \& Olynyk JK. NAFLD as a risk factor for the development of diabetes and the metabolic syndrome: an eleven-year follow-up study. American Journal of Gastroenterology $2009 \mathbf{1 0 4} 861-867$. (doi:10.1038/ajg. 2009.67)

16 Farrell GC \& Larter CZ. Nonalcoholic fatty liver disease: from steatosis to cirrhosis. Hepatology 200643 (2 Suppl 1) S99-S112. (doi:10.1002/hep.20973)

17 Dancygier H. The pathogenesis and treatment of nonalcoholic fatty liver diseases - from fatty liver to cirrhosis. Deutsches Ärzteblatt 2006103 1301-1307.

18 Angelico F, Del Ben M, Conti R, Francioso S, Feole K, Maccioni D, Antonini TM \& Alessandri C. Non-alcoholic fatty liver syndrome: a hepatic consequence of common metabolic diseases. Journal of Gastroenterology and Hepatology 200318 588-594. (doi:10.1046/ j.1440-1746.2003.02958.x)

19 Shen YH, Yang WS, Lee TH, Lee LT, Chen CY \& Huang KC. Bright liver and alanine aminotransferase are associated with metabolic syndrome in adults. Obesity Research 200513 1238-1245. (doi:10.1038/oby.2005.147)
20 Pfutzner A, Kunt T, Hohberg C, Mondok A, Pahler S, Konrad T, Lübben G \& Forst T. Fasting intact proinsulin is a highly specific predictor of insulin resistance in type 2 diabetes. Diabetes Care 200427 682-687. (doi:10.2337/diacare.27.3.682)

21 Zethelius B, Byberg L, Hales CN, Lithell H \& Berne C. Proinsulin and acute insulin response independently predict type 2 diabetes mellitus in men-report from 27 years of follow-up study. Diabetologia 200346 20-26.

22 Pradhan AD, Manson JE, Meigs JB, Rifai N, Buring JE, Liu S \& Ridker PM. Insulin, proinsulin, proinsulin:insulin ratio, and the risk of developing type 2 diabetes mellitus in women. American Journal of Medicine 2003114 438-444. (doi:10.1016/S00029343(03)00061-5)

23 Alssema M, Dekker JM, Nijpels G, Stehouwer CD, Bouter LM, Heine RJ \& Hoorn Study. Proinsulin concentration is an independent predictor of all-cause and cardiovascular mortality: an 11-year follow-up of the Hoorn Study. Diabetes Care 200528 860-865. (doi:10.2337/diacare.28.4.860)

24 Oh JY, Barrett-Connor E \& Wedick NM. Sex differences in the association between proinsulin and intact insulin with coronary heart disease in nondiabetic older adults: the Rancho Bernardo Study. Circulation 2002105 1311-1316. (doi:10.1161/hc1102.105565)

25 Haenle MM, Brockmann SO, Kron M, Bertling U, Mason RA, Steinbach G, Boehm BO, Koenig W, Kern P, Piechotowski I et al. Overweight, physical activity, tobacco and alcohol consumption in a cross-sectional random sample of German adults. BMC Public Health 20066 233. (doi:10.1186/1471-2458-6-233)

26 WHO Expert Committee on Physical Status. The Use and Interpretation of Anthropometry: report of a WHO expert comitee (WHO technical report service) Genf, Switzerland: World Health Organization; 1995 427-37.

27 Friedewald WT, Levy RI \& Fredrickson DS. Estimation of the concentration of low-density lipoprotein cholesterol in plasma, without use of the preparative ultracentrifuge. Clinical Chemistry 197218 499-502.

28 Gardner DG \& Shoback D. Greenspan's Basic and Clinical Endocrinology, 8th edn. pp 661-669. New York: Lange/McGraw-Hill, 2007.

29 Saverymuttu SH, Joseph AE \& Maxwell JD. Ultrasound scanning in the detection of hepatic fibrosis and steatosis. BMJ 1986292 13-15. (doi:10.1136/bmj.292.6512.13)

30 Hamaguchi M, Kojima T, Itoh Y, Harano Y, Fujii K, Nakajima T, Kato T, Takeda N, Okuda J, Ida K et al. The severity of ultrasonographic findings in nonalcoholic fatty liver disease reflects the metabolic syndrome and visceral fat accumulation. American Journal of Gastroenterology $2007 \mathbf{1 0 2} 2708-2715$. (doi:10.1111/j.1572-0241.2007.01526.x)

31 Charatcharoenwitthaya P \& Lindor KD. Role of radiologic modalities in the management of non-alcoholic steatohepatitis. Clinics in Liver Disease 200711 37-54, viii. (doi:10.1016/j.cld.2007.02.014)

32 Pivatto I, Bustos P, Amigo H, Acosta AM \& Arteaga A. Association between proinsulin, insulin, proinsulin/insulin ratio, and insulin resistance status with the metabolic syndrome. Arquivos Brasileiros de Endocrinologia e Metabologia 200751 1128-1133. (doi:10.1590/S0004-27302007000700016)

33 Strawbridge RJ, Dupuis J, Prokopenko I, Barker A, Ahlqvist E, Rybin D, Petrie JR, Travers ME, Bouatia-Naji N, Dimas AS et al. Genome-wide association identifies nine common variants associated with fasting proinsulin levels and provides new insights into the pathophysiology of type 2 diabetes. Diabetes $20116 \mathbf{6 0}$ 2624-2634. (doi:10.2337/db11-0415)

34 Caballeria L, Pera G, Auladell MA, Toran P, Munoz L, Miranda D, Aluma A, Casas JD, Sanchez C, Gil D et al. Prevalence and factors associated with the presence of nonalcoholic fatty liver disease in an adult population in Spain. European Journal of Gastroenterology \& Hepatology 201022 24-32. (doi:10.1097/ MEG.0b013e32832fcdfo)

35 Bajaj S, Nigam P, Luthra A, Pandey RM, Kondal D, Bhatt SP, Wasir JS \& Misra A. A case-control study on insulin resistance, metabolic co-variates \& prediction score in non-alcoholic fatty liver disease. Indian Journal of Medical Research $2009 \mathbf{1 2 9}$ 285-292. 
36 Ardigo D, Numeroso F, Valtuena S, Franzini L, Piatti PM, Monti L, Delsignore R, Reaven GM \& Zavaroni I. Hyperinsulinemia predicts hepatic fat content in healthy individuals with normal transaminase concentrations. Metabolism $2005 \quad \mathbf{5 4}$ 1566-1570. (doi:10.1016/j.metabol.2005.05.027)

37 Burgert TS, Taksali SE, Dziura J, Goodman TR, Yeckel CW, Papademetris X, Constable RT, Weiss R, Tamborlane WV, Savoye M et al. Alanine aminotransferase levels and fatty liver in childhood obesity: associations with insulin resistance, adiponectin, and visceral fat. Journal of Clinical Endocrinology and Metabolism 2006 91 4287-4294. (doi:10.1210/jc.2006-1010)

38 Hanley AJ, McKeown-Eyssen G, Harris SB, Hegele RA, Wolever TM, Kwan J \& Zinman B. Cross-sectional and prospective associations between abdominal adiposity and proinsulin concentration. Journal of Clinical Endocrinology and Metabolism $2002 \mathbf{8 7}$ 77-83. (doi:10.1210/jc.87.1.77)

39 Bryhni B, Arnesen E \& Jenssen TG. Associations of age with serum insulin, proinsulin and the proinsulin-to-insulin ratio: a crosssectional study. BMC Endocrine Disorders $2010 \quad 1021$. (doi:10.1186/1472-6823-10-21)

40 Speliotes EK, Yerges-Armstrong LM, Wu J, Hernaez R, Kim LJ, Palmer CD, Gudnason V, Eiriksdottir G, Garcia ME, Launer LJ et al. Genome-wide association analysis identifies variants associated with nonalcoholic fatty liver disease that have distinct effects on metabolic traits. PLoS Genetics 20117 e1001324. (doi:10.1371/ journal.pgen.1001324)

41 Romeo S, Kozlitina J, Xing C, Pertsemlidis A, Cox D, Pennacchio LA, Boerwinkle E, Cohen JC \& Hobbs HH. Genetic variation in PNPLA3 confers susceptibility to nonalcoholic fatty liver disease. Nature Genetics 200840 1461-1465. (doi:10.1038/ ng.257)

42 Wareham NJ, Byrne CD, Williams R, Day NE \& Hales CN. Fasting proinsulin concentrations predict the development of type 2 diabetes. Diabetes Care 199922 262-270. (doi:10.2337/diacare. 22.2.262)

43 Joseph AE, Saverymuttu SH, al-Sam S, Cook MG \& Maxwell JD. Comparison of liver histology with ultrasonography in assessing diffuse parenchymal liver disease. Clinical Radiology $1991 \mathbf{4 3}$ 26-31. (doi:10.1016/S0009-9260(05)80350-2)

Received 3 April 2012

Revised version received 29 October 2012

Accepted 7 November 2012 